\title{
El proyecto anti-racista del mestizaje. Manuel Zapata Olivella*
}

\author{
Carlos Alberto Valderrama Renteria ${ }^{1}$ \\ Universidad Icesi
}

ORCID: 0000-0001-8838-8350

Recibido: 11 de febrero de 2020

Aceptado: 12 de abril de 2020

\section{RESUMEN}

En el presente escrito, se rastrea la idea de mestizaje en el pensamiento crítico afrocolombiano del intelectual Manuel Zapata Olivella. Se sostiene que su noción de mestizaje planteó alternativas al mestizaje dominante de las elites nacionales de Colombia. Para este objetivo, se propone entender el mestizaje como un terreno o campo de confrontación política e ideológica entre regímenes de conocimiento y poder que se disputan la hegemonía y el control discursivo sobre su significado. Así, la idea de mestizaje en el pensamiento intelectual de Manuel Zapata Olivella es una de las propuestas intelectuales que buscó disputar el significado de mestizaje desde el abajo racializado.

Palabras clave: Mestizaje, pensamiento crítico, anti-racismo, intelectualidad.

\begin{abstract}
This paper track the idea of mestizaje in the political thought of afrocolombian intellectual Manuel Zapata Olivella. It argues that this notion of mestizaje stated an alternative meaning different from the elite's idea of mestizaje. To fulfill this goal, the paper proposes to understand mestizaje as a terrain or field of political and ideological confrontation between regime of knowledge and power that disputes the hegemony and discursive control over the meaning of mestizaje. Thus, Manuel Zapata's idea of mestizaje challenges the hegemony idea of mestizaje from the racialized below.
\end{abstract}

Keywords: Mestizaje, critical thought, anti-racism and intellectuality.

\section{INTRODUCCIÓN}

La idea de mestizaje se encuentra fuertemente asociada a la dominación racial cuando se trata del lugar que ocupan las comunidades negras en la "comunidad imaginada" de la nación colombiana. Ni la versión conservadora (predominante entre 1886 y 1930) ni la liberal (predominante durante la República Liberal,1930-1946) del mestizaje valoraron, realmente, los aportes y/o presencias afrocolombianas en el país. Según se puede entender, la ideología del mestizaje fue utilizada para

\footnotetext{
*The anti-racist project of mestizaje. Manuel Zapata Olivella

${ }^{1}$ Trabajador Social de la Universidad del Valle. Magister y PhD en Sociología por la Universidad de Massachusetts, Amherst, (Estados Unidos). Especialización en Estudios afrodiaspóricos y latinos por la misma universidad. Profesor del departamento de Sociología de la Universidad Icesi e investigador asociado al Centro de Estudios Afrodiaspóricos-CEAF. Correo: pibeson@gmail.com
} 
ocultar el verdadero proyecto racial de blanquear la nación. Ya sea a través de migrantes europeos que poblaran la nación o a través de programas de educación, higiene y progreso (Wade, 1993 y Pisano, 2010). De ahí que proponer una mirada del mestizaje como propuesta contra-hegemónica pudiera sonar extraña; más aún si se la concibe como anti-racista. Sin embargo, estudios han demostrado que el mestizaje también sirvió como estrategia de resistencia. Ya sea como fuerza liberadora de las clasificaciones raciales de opresión colonial y postcolonial (Mellon,1996: 171); una historia negra por contar (Zapata-Cortes, 2010); una manera no común de hibridez indígena que resiste a la biopolítica cultural del mestizaje (de la Cadena, 2006: 73); una epistemología del sincretismo inclusiva (Arboleda, 2010: 456); o como un proyecto de nación inclusiva (Múnera, 2010). Mestizaje, así entendido, se convierte en un mosaico de significados que se disputan formas de mestizajes excluyentes e inclusivas (Wade, 2005). Por ello, "el mestizaje es mejor definido como un diálogo político -estratificado y abierto- articulado por una densa red intertextual que incluía escritos literarios y científicos, eventos artísticos y políticos, murales y pinturas, museos y políticas estatales, entre otros." (de la Cadena, 2006: 68).

El presente escrito explora algunos sentidos no dominantes del mestizaje. Considero que algunos de estos se han vuelto "obvios y [...] [han] marginalizado otros que circulan 'escondidos' en significados dominantes." (de la Cadena, 2006: 55). Mi objetivo es revisar la idea de mestizaje en los escritos sobre folclore y cultura del intelectual afrocolombiano Manuel Zapata Olivella con el propósito de probar que su idea de mestizaje refleja una agenda anti-racista (Arboleda, 2016) propia del pensamiento crítico afrocolombiano. Sostengo que su noción de mestizaje plantea una alternativa al mestizaje hegemónico de mitad de siglo XX en Colombia y en América Latina. Más allá de sus ambigüedades, su propuesta de mestizaje fue anti-racista en tanto se inscribió en un pensamiento que denunció el racismo a la colombiana y reafirmó y/o revaloró una identidad cultural que humanizó a las comunidades negras e indígenas como parte de lo que él llamo "pueblo vivo". Ahora, ¿qué tanto se distanció su idea de mestizaje de aquellas diseñadas por las elites nacionales para la dominación racial? Esta será uno de los interrogantes que guiará el análisis sobre los sentidos atribuidos al mestizaje propuesto por Manuel Zapata Olivella.

En este escrito se entiende mestizaje desde la teoría critica de la raza. Se define como un proyecto racial diseñado para la dominación racial (Omi and Winant, 1994). Mestizaje fue y sigue siendo un mecanismo discursivo utilizado por las elites blanco-mestizas con el propósito de mantener un orden racial que les permita mantener privilegios sociales, económicos y políticos bajo la idea de nación mestiza, armonía y/o democracia racial (de la Cadena, 2000; Pisano, 2010; y Wade, 1993). Como vimos anteriormente, a esta visión dominante se le anteponen significados múltiples de mestizaje. Por eso, para el presente estudio entiendo el mestizaje como un terreno de confrontación política e ideológica entre regímenes de conocimiento y poder que se disputan la hegemonía y el control discursivo sobre su significado (Valderrama, 2013). La idea de mestizaje en el pensamiento intelectual de Manuel Zapata Olivella es una de las propuestas intelectuales que buscó, desde el abajo racializado y subalterno, disputar su significado contra la idea de mestizaje enunciado desde las elites nacionales. 
Mi estrategia metodológica fue la siguiente: hice un análisis sociológico del pensamiento intelectual de Manuel Zapata Olivella rastreando su política cultural negra, entendida como aquellos procesos de pensamiento intelectual, social y cultural de sujetos que se implican en acciones o prácticas organizativas para disputar el significado de una representación cultural y/o racial en el campo de la política, el pensamiento y la producción académica. En este caso, me centré en la política cultural del folclore negro. Analicé sus escritos y ensayos sobre folclore colombiano publicados en revistas nacionales entre los años 1945 y 1960. Este no solo fue un periodo en el cual el gobierno nacional implementó reformas políticas, sociales y culturales para la modernización de Colombia y el "mejoramiento de la raza", sino que también nos ubica en esos primeros trabajos de Manuel Zapata Olivella influenciados por los estudios de Fernando Ortiz, los estudios folclóricos y la perspectiva afroamericanista; perspectivas etnográficas y antropológicas cuyos análisis sobre las relaciones de poder racial estuvieron ausentes. Así, sostengo que el pensamiento anti-racista de Manuel Zapata Olivella se fue definiendo mucho antes que pudiéramos encontrar en sus textos la influencia de la negritud (ver, por ejemplo, Arboleda, 2010 y Viveros, 2013). Para el presente trabajo he tomado algunos de sus escritos compilados por Alfonso Múnera bajo el nombre de Manuel Zapata Olivella, por los senderos de sus ancestros. Otros los tomé de la Revista de Folclore Colombianos y de Cromos. Mi principal tarea fue analizar los usos, sentidos y asociaciones otorgadas a la palabra mestizaje. Lo anterior fue combinado con fuentes secundarias que han estudiado el tema de mestizaje en Colombia y en América Latina, así como también algunos estudios sobre la trayectoria intelectual de Manuel Zapata Olivella.

\section{Manuel Zapata Olivella. Un intelectual de pensamiento crítico y acciones políticas}

Manuel Zapata Olivella, antropólogo, literato, médico, dramaturgo y activista, nació el 17 de marzo de 1920 en Lorica, Córdoba, y murió el 19 de noviembre del 2004 en Bogotá. Hijo de Antonio Zapata, afrocolombiano, y de Edelmira Olivella, mestiza resultado de la mezcla entre indígenas y españoles, Manuel Zapata Olivella representó en sí mismo una mezcla racial que conforma no solo la identidad regional del Caribe colombiano sino que también lo que luego llamó como "el pueblo vivo" (Zapata, 2010:199): un mestizaje multi-racial y étnico radical; identidad racial que definió los linderos de una intelectualidad de acción política y de pensamiento crítico contra las injusticias sociales y raciales. Junto con sus hermanos Juan (1922-2008) y Delia Zapata Olivella (1924-2001), emprendió una lucha titánica

por la inclusión de lo negro y el reconocimiento de su participación en el proceso de construcción de [...] [una] nación [mestiza radical], en un contexto social que hacía la glorificación de lo mestizo [...] que apuntalaba un discurso jerárquico de lo blanco, discriminado lo indígena y lo negro. (Viveros, 2013: 465)

Desde muy temprana edad, la trayectoria intelectual de Manuel Zapata Olivella estuvo marcada por sus profundas reflexiones y denuncias de injusticias raciales, así como de acciones políticas para transformarlas. Habiendo migrado a Bogotá para terminar sus estudios sobre medicina en la Universidad Nacional de Colombia, Manuel Zapata Olivella fue interpelado por representaciones 
raciales construidas sobre personas como él. Estas representaciones encontraron respuesta por parte de un grupo de intelectuales costeños dentro de los que se encontraban Antonio Brugés Carmona, Gabriel García Márquez y Manuel Zapata Olivella, entre otros. En respuesta a estos comentarios racistas, Zapata publicó “Genio y figura" (1942) y "El porro conquista a Bogotá" (192). En estos trabajos hizo una defensa de la identidad cultural costeña. Menciona a los artistas musicales que han contribuido al enriquecimiento musical del folclore nacional, y afirma, de manera clara y sin complejos, la relación entre la música costeña y la discriminación racial (Zapata Olivella, 2010: 54). En la práctica, junto con su hermana Delia Zapata Olivella, organizaron encuentros de la colonia costeña en Bogotá donde podían escuchar y bailar la música de su región (Caicedo, 2013).

La confrontación con el racismo capitalino lo motivó a escudriñar el nudo de los complejos raciales (Zapata Olivella, 1990), tarea intelectual que inició, según el mismo Zapata, con "encuentros capitalinos en pensiones, aulas y calles", donde

discutíamos, sin saberlo, lo más importante de la formación humanística: nuestra propia identidad. "Tú eres negro, Yo soy mulato". "Todos somos discriminados" [...] Paulatinamente, dolorosamente, al lado de mi hermana (Delia Zapata) principiamos a desatar el nudo de los complejos raciales inconscientes. (Zapata Olivella, 1990:184)

De las pensiones, las aulas y las calles, Manuel Zapata Olivella pasó a la protesta. Participó de las acciones colectivas que conmemoraron el Día del Negro $(1943)^{2}$ y de la creación del El Club Negro de Colombia (1943). Para Pietro Pisano, el Día del Negro y el Club Negro de Colombia reflejan el "lugar ocupado por la gente negra en la sociedad colombiana en la primera mitad del siglo XX, pero también un primer intento de redefinirlo y tratar de solucionar algunos problemas específicos de esta población" (2010:107). Así como estas acciones colectivas denunciaron el racismo, la invisibilidad y el estatus de segunda clase de la gente negra en la sociedad colombiana, Manuel Zapata Olivella también alzó sus manos para denunciar el racismo, la invisibilidad y el estatus de segunda clase de la gente negra en la academia colombiana. Estas denuncias contra el racismo también se pueden ver expresadas en trabajos escritos como "Harlem Olvidado", "La raza negra y el arte", "El drama de los latinos" y "Vasconcelos, filósofo de la conquista", publicados en el seminario Sábado entre 1948 y 1951. Según Mara Viveros, estos escritos "recogen los temas que lo acompañaron a lo largo de su trayectoria vital: las desigualdades sociales y sus vínculos con la discriminación racial; [...].” (2013: 471-472).

De la protesta y la denuncia del racismo, Manuel Zapata Olivella pasó a la propuesta. A su regreso de su periplo por Centro y Norteamérica, experiencias vitales de las cuales publicó posteriormente

${ }^{2}$ En la marcha participaron al menos doce estudiantes negros universitarios entre los cuales se encontraban Natanael Díaz, Adolfo Mina Balanta y Marino Viveros, originarios del norte del Cauca; Delia y Manuel Zapata Olivella de Lorica, el Caribe colombiano; y estudiantes del Pacífico norte, Chocó. 
Pasión vagabunda (1948) y He visto la noche (1952), fundó el Centro de Estudios Afrocolombianos en 1947 en Bogotá, año en el que también publicó su novela Tierra Mojada. El Centro de Estudios Afrocolombianos fue una iniciativa cultural y académica en la que participaron intelectuales, políticos, poetas, y folkloristas provenientes de la región del Pacífico y del Caribe colombiano ${ }^{3}$. Su propuesta contempló cuatro áreas de trabajo investigativo: a. Estudios históricos; b. Estudios etnológicos; c. Estudios lingüísticos; y d. Influencias de los grupos raciales en Colombia (Karabalí, 1947). Aunque el Centro buscó profundizar estudios afrocolombianos similares a los realizados con los grupos indígenas (Karabalí,1947), desde una perspectiva afrodiaspórica, su agenda concuerda con el llamado hecho por centros de estudios afroamericanistas. De ahí la presencia de Fernando Ortiz, de Cuba y Arturo Ramos, de Brasil como miembros honorarios, y el deseo de intercambios académicos entre los centros de estudio afroamericanistas en Cuba, Brasil y México (Karabalí,1947: 9).

Las áreas de investigación propuestas por el Centro de Estudios Afrocolombianos muestran una agenda antirracista que pretendió hacer visible aquello que la elite colombiana negó y ocultó como elementos constitutivos de la nación colombiana: la existencia de una historia y cultura milenaria negras en Colombia, heredera de las sociedades africanas y transculturada a lo ancho del país. Aunque no se han encontrado registros sobre las actividades investigativas del Centro durante los años ' 50 y ' 60 , muy probablemente su dinámica investigativa fue impactada negativamente por los acontecimientos surgidos con el asesinato del líder político liberal Jorge Eliécer Gaitán, en 1948, y la criminalización de la protesta social y política. Fue en este periodo cuando Manuel Zapata Olivella y otros líderes políticos afrocolombianos fueron perseguidos y, en otros casos, exiliados por su pensamiento de izquierda y filiación política al Partido Comunista colombiano (Valderrama, 2019).

Con la salida de Bogotá, Manuel Zapata comenzó su activismo cultural. Se unió con su hermana Delia Zapata para realizar trabajos etnográficos y, desde ahí, promocionar las culturas subalternas a través de grupos de danzas coreográficos. Primero internándose en veredas, ríos y poblados del Caribe colombiano y de la región Pacífica para observar, registrar y entender, a través de los ojos de los propios pobladores campesinos, las visiones, historias y significados de prácticas y actividades rituales de las tradiciones locales. Por ejemplo, la distinción entre danzas sacras y profanas (Zapata Olivella, 1985:11). Manuel Zapata Olivella recuerda que la sabiduría y conocimiento de los mayores, bailarines y campesinos locales, fueron fundamentales en la reconstrucción histórica no sólo de la danza, los instrumentos musicales y el vestuario, sino también las particularidades de cada región de Colombia. Para lo anterior, fue muy importante "convertirse en alumnos atentos, repetidores como otro magnetófono, de cuanto veíamos y escuchábamos de nuestras maestras ancianas. Repetíamos los pasos descalzos de la abuela campesina” (Zapata Olivella, 1985). Precisamente,

\footnotetext{
${ }^{3}$ Entre sus miembros estuvieron los afrocolombianos César Alonso, Marino Viveros, Carlos Calderón Mosquera, Delia Zapata Olivella, Baldomero Sanín Cano, Alberto Miramón, Natanael Díaz, Diego Luis Córdoba, Dulcey Vergara, y Guillermo Naneti; e intelectuales mestizos y blancos, Gregorio Hernández de Alba, y Duque Gómez.
} 
en trabajos como "Los Negros palenqueros", "Del folclore colombiano", "Razones del mestizaje folclórico colombiano", "Los pasos del folclore colombiano", "Aculturación del arte popular colombiano", "Aportes materiales y psicoactivos del negro en el folclore colombiano", "Qué sabemos de los negros en Colombia”, entre otros, publicados en diversas revistas y seminarios nacionales durante los años ‘ 50 y ‘60, el lector encontrará la manera en la que Manuel Zapata reflejó sus estudios etnográficos sobre la cultura nacional.

No podemos olvidar que algunos de quienes conformaron sus primeros grupos folclóricos de danza fueron campesinos, labriegos, pescadores o personas de común, experiencia de reclutamiento registrada en el artículo "Del folclor colombiano" publicado en 1953 (Zapata Olivella, 2010:104). Entre otros, Lorenzo Miranda, Batata y los Gaiteros de San Jacinto, del Atlántico, y Totó la Mompoxina, Leonor González Mina, Madolia de Diego y Esteban Cabezas de la región Pacífica. Los hermanos Zapata Olivella no solo viajaron por toda Colombia mostrando la música, danzas, vestuarios e instrumentos musicales de estas regiones, sino que también lo hicieron por Europa y Suramérica. Comparto con Viveros (2013) que es necesario reconocer los aportes que hicieron los hermanos Zapata Olivella por la difusión de la tradición musical y danzaria de los sectores populares y afrocolombianos, no solo desconocida sino también desvalorizada como música vulgar o "música de negros". Lo que mucha gente no sabe o no reconoce de las danzas coreográficas es que fueron en sí mismas el medio utilizado para dar a conocer las formas de vida locales de estos grupos étnicos y raciales. Para Delia y Manuel Zapata Olivella, las danzas y producciones coreográficas eran estampas culturales, ya que las danzas teatralizaban la vida cotidiana de campesinos afrocolombianos e indígenas. Así, proyectaron aspectos de la vida local tales como la música e instrumentos musicales; tradición oral (cuentos, leyendas, mitos, décimas, cantos, etc.); religiosidad (adoraciones, alabaos, arrullos, chigualos, etc.); bailes (de laboreo, profanas, de coqueteo, etc.); y una estética cultural en el vestuario y peinados. En este orden de ideas, estudiaron y montaron danzas coreográficas populares no sólo por estética o disfrute. Observaron en las danzas la "posibilidad de refundar la nación a partir de una memoria histórica compartida, que permea todo el territorio nacional, pero que también permite explicar satisfactoriamente las diferencias regionales, culturales y raciales." (Zapata-Cortés, 2010: 95).

El activismo cultural de Manuel Zapata Olivella y su hermana les permitió construir una red de relaciones y colaboraciones entre músicos, folcloristas, cantantes, bailarines y compositores. Red que se ampliaría entre los años '60 y '70 con la creación de la Fundación Colombiana de Investigaciones Folclóricas, la revista Letras nacionales, la creación y emisión de programas folclóricos en la radio difusora nacional de Colombia; la creación del Teatro Anónimo Identificador (similar al Teatro del oprimido) con el que recorrió varias plazas y parques de Colombia presentando obras como Rambao; y la re-apertura del Centro de Estudios Afrocolombianos. Todo lo anterior, con una intención explícita de visibilizar el nacionalismo literario, el folclore colombiano y la cultura popular. Podemos señalar que Manuel Zapata Olivella fue uno de los pioneros en los estudios de la cultura y la historia nacional que incluyó un énfasis en los aportes culturales de la gente negra a la 
Carlos Alberto Valderrama Renteria

nación colombiana en un momento histórico donde la mayoría de los investigadores colombianos en el campo de la historia y la antropología desecharon el estudio de la cultura e historia afrocolombiana y su relación con África, la trata esclavista, la explotación y la discriminación racial. Y es que, según él, faltaba mucho "por realizar para que se diga entre nosotros que a tal o cual cultura indígena o africana se debe éste o aquel rasgo peculiar de nuestro pueblo, [...]." (Zapata Olivella, 1956). Por ello, a Manuel Zapata Olivella hay que entenderlo como uno de los pocos pensadores colombianos del siglo XX cuya intelectualidad se definió por un pensamiento crítico que cuestionó la ausencia de estudios enfocados a las comunidades afrocolombianas; y de acciones políticas que concretaron propuestas que buscaron transformar la mirada racializadora que sobre las comunidades negras tuvo la sociedad colombiana.

Como veremos a continuación, la lectura que Zapata hizo del mestizaje entre los años 1943 y 1967 en Colombia advierte la existencia de relaciones de poder raciales. Es decir, el mestizaje como el resultado de procesos de dominación racial y no necesariamente como actos humanos de libre reciprocidad.

\section{Mestizaje en el pensamiento crítico anti-racista}

Una manera de rastrear el pensamiento anti-racista en el pensamiento crítico de Manuel Zapata Olivella puede ser a través del análisis de los sentidos (usos y propósitos) otorgados al término mestizaje. Justamente, al tiempo que Manuel Zapata nos informa acerca de las "circunstancias históricas, geográficas y raciales de Colombia, [que] prohijaron más que en cualquier otro país la síntesis unitaria de las culturas" (Zapata Olivella, 2010:121), denunció la discriminación racial y valoró, positivamente, los aportes culturales que las comunidades negras han hecho a la cultura nacional en un contexto histórico marcado por su desprecio y rechazo.

Desde muy temprano encontramos esta vocación crítica y propositiva en los escritos de Manuel Zapata. De hecho, en 1942, a la edad de 22 años, Manuel Zapata publicó un ensayo sobre las implicaciones de la migración costeña en Bogotá. Para ese entonces, la música costeña se había tomado con éxito la sociedad capitalina:

El Caribe deja escuchar sus cantares impregnados de algarabía africana en los picachos andinos. No pocos son los rasgos que acentúan en el capitalino, como productos del mestizaje de los glóbulos mulatos disociándose cual pincelada alegre en la acuarela gris del viejo santafereño. (Zapata Olivella, 2010: 53)

Para Zapata Olivella, el impacto de la música costeña en Bogotá había sido tal que los suicidios habían disminuidos (Zapata Olivella, 2010: 60). Sin embargo, la élite intelectual y política de Bogotá no vio con buenos ojos esta incursión cultural del mestizaje mulato costeño. Locutores, intelectuales y periodistas capitalinos hicieron comentarios con mucha hostilidad y desprecio racial hacia la música costeña. Consideraban que eran expresiones musicales (ej. la cumbia, la puya, el 
paseo, mapalé, el fandango, el bullarengue, etc.) desagradables, licenciosas, salvajes, grotescas, vulgares y muy negras (Wade, 2000: 125-130).

Manuel Zapata fue consciente de este rechazo hacia la música costeña por su visible influencia cultural negra y africana -la "unidad de la costa, unidad en la música y en el espíritu, campea en la fraternal danza negra" (2010:60)-, y la defendió como un aporte significativo a la cultura nacional: "Aun cuando los sociólogos quieran ignorarlo, el porro, como rasgo protuberante de la migración mulata hacia la capital, tiene una gran significación" (2010: 53). En medio de estas tensiones raciales, "la música que se quería rechazar injustamente $[\mathrm{p}]$ or encima de todo, $[\ldots]$ progresaba". Solo encontraba censura por parte de "los racistas criollos [...] que han obstaculizado el advenimiento de esta era que podríamos llamar aurora de un renacimiento negro" (2010: 53). Por supuesto, el renacimiento negro no solo fue una referencia intertextual del renacimiento de Haití y de Harlem, sino que también hizo alusión al jazz, el son, el mambo, la rumba, la cumbia, el porro, etc., que dominaron a inicio del siglo XX y que tienen una fuerte influencia africana en sus orígenes. No en vano, el "espíritu cósmico de América se revelaba en aquella música [americana y] colombiana." (Zapata Olivella, 2010: 59).

En contraste, Manuel Zapata describe cómo los sectores populares abrazaron el renacimiento negro: "En los sitios más populares era acogida entusiásticamente, cambiando, de hecho, la psicología ambiental. Así surgieron las tardes y noches en el Café Palacio, foco de atracción de bogotanos y costeños que se estimulaban con la trompeta de Acosta Calderón." (Zapata Olivella, 2010: 58). De acuerdo con lo anterior, mientras la elite despreciaba la aurora del renacimiento negro, los sectores populares la abrazaban. En barrios, calles y bailaderos, la música costeña circulaba al tiempo que se preservaba. Sin embargo, Manuel Zapata denunció que,

El desaire más grande que se le hubiera hecho al porro y a la música popular colombiana tuvo lugar cuando a un concurso patrocinado por el Ministerio de Educación, en el cual se llamó a participar a todos los compositores populares [...] se le quiso dar aire [blanquear con el molde de la música] clásico. Aquello fue un insulto hecho a nuestros compositores populares. (2010: 58)

El pensamiento crítico de Manuel Zapata Olivella revela las tensiones raciales y de clase que se produjeron por la popularidad de la música costeña, que, como sabemos, hace parte de ese Caribe heredero de la herencia africana. Herencia cultural que la academia colombiana desestimó como campo de estudio. Manuel Zapata sostuvo, "[c]ualquier aspecto del folclor negro en Colombia que se quiera estudiar encuentra el inconveniente del desconocimiento de su origen africano. Mientras no se realicen trabajos serios sobre la transculturación africana a nuestro país, el conocimiento científico sobre el folclor negro será un gran problema de interpretación." (Zapata Olivella, 2010: 82). Un ejemplo de lo anterior, Manuel Zapata lo ilustra con el caso de la cumbia, el cual sabemos que "[...], tiene un origen netamente africano. Sin embargo, cuando se quiere saber qué cultura negra le dio origen o facilitó su supervivencia en el país, nos encontramos que se desconocen los 
Carlos Alberto Valderrama Renteria

lazos de este baile con sus similares africanos" (Zapata Olivella, 2010: 82), planteamientos que se pueden encontrar en "Del folclore musical" y "Del folclore colombiano".

Uno podría sugerir que Manuel Zapata denunció y/o reveló los “silenciamientos” que la academia colombiana cometió contra las herencias negras y africanas en nuestro país. Quince años después de haber llamado la atención sobre la necesidad de realizar estudios serios sobre la transculturación africana, Manuel Zapata Olivella se preguntó “¿Qué sabemos de los negros en Colombia?” (1956), en un artículo publicado en Cromos sobre el folclor colombiano. En este, Manuel insistió que en "Colombia estamos en mora con el estudio científico de la transculturación africana" (33). Y como él, Rogerio Velázquez, Aquiles Escalante y Delia Zapata Olivella reclamaron exactamente lo mismo: la necesidad imperiosa de realizar estudios serios sobre la cultura negra y africana en Colombia (Valderrama, 2013: 274). Para Manuel Zapata, lo único que pudiera explicar la inexistencia de estudio sobre la transculturación africana es lo que hoy en día se denomina racismo epistémico. En sus palabras:

Si no existiera el mismo desapego por el estudio de muchas de las comunidades indígenas de nuestro país, podría afirmarse con cierta certidumbre que el descuido por estas investigaciones se debe a un prejuicio racial estúpido por desenterrar los antepasados que nos dieron fisonomía de pueblos libres ante el temor de encontrar de pie, erguido y altanero, al viejo bisabuelo que desde las bodegas de los barcos negreros reclama el reconocimiento de sus claros timbres en la conquista y en la formación de la Nueva América. Pero aun cuando se quiera disimular tal prejuicio, lo cierto es que en nuestro país existe un intencionado silencio en lo que respecta a reconocer la gran epopeya del indio y del negro, [...]. (1956: 32)

Las anteriores líneas son muy reveladoras e ilustrativas de una posible explicación sobre la ausencia del negro y la presencia-ausencia de las comunidades indígenas en los inicios de la antropología colombiana. Se ha dicho que la ausencia del negro se debió a la construcción de criterios de pertinencia y relevancia disciplinar. Sin embargo, Manuel Zapata Olivella, que vivió y experimentó ese periodo histórico, afirma que fue el racismo epistémico lo que no permitió el desarrollo de estudios culturales afrocolombianos en ese momento; afirmación que en los años ' 80 fue respaldada por una de las antropólogas más importantes del país, Nina S. de Friedemann (1984). En mi opinión, Manuel Zapata Olivella va más allá de la crítica hecha por la autora. Sugiere que la razón detrás de la ausencia de estudios negros en la antropología se debe al "temor de encontrar de pie, erguido y altanero, al viejo bisabuelo que desde las bodegas de los barcos negreros reclaman el reconocimiento de sus claros timbres en la conquista y en la formación de la Nueva América." (32). En otras palabras, Zapata reveló una hipocresía racista de la élite intelectual y política de Colombia al negarse a ellos mismos sus "trazos inconscientes de la africanía” (Zapata Olivella, 1998a: 110):

En lo que respecta la transculturación del negro en Colombia parece que ni siquiera ha surgido el propósito sincero de enfrentarse al problema. Se calla, se desatiende y tal vez hasta se quiera 
enterrar como si la historia y más aún la biología de un pueblo, pudiera mantenerse eternamente detrás de una máscara. (Zapata Olivella, 1956: 32)

Se niega la ausencia de la cultura negra, para poder afirmar lo blanco como constitutivo de los cuerpos humanos y culturas que componen la nación. Lo anterior explica el siguiente comentario, "Aun cuando nos desentendamos de estos aspectos de nuestra cultura, avergonzándonos tal vez, la sed de conocimiento de otros pueblos, [...] nos trae muchos investigadores [...]" extranjeros. "Para ellos la verdad monda y lironda es mucho más fundamental que el silencio y los sentimientos humillantes" (Zapata Olivella, 1956: 32) .

Se puede sostener que los reclamos hechos por Manuel Zapata Olivella develaron las entrañas del proyecto racial del blanqueamiento: la eliminación simbólica y material de la gente negras e indígenas del imaginario e historia nacional. Proyecto racial de blanqueamiento que promulgó reformas educativas, eugenésicas, y la traída de inmigrantes blancos europeos con el objetivo de obtener el progreso, la producción industrial y la estabilidad social y política en Colombia sin la presencia de comunidades negras e indígenas. Como lo demuestra Pisano, estás políticas de blanqueamiento continuaron hasta mitad de los años 50 en Colombia, a diferencia de otros países de Latinoamérica, para "salvar al país de su decaimiento." (2010: 52). Así lo describe el mismo Manuel Zapata:

En los herederos criollos del poder colonial persiste la actitud discriminatoria y peyorativa hacia los elementos culturales del indio o el negro. [Mientras e]n la gran masa del pueblo, obligada a vivir en las condiciones paupérrimas a que fue sometida desde el primer día de la Conquista, bulle un afán inconsciente de aferrarse a sus expresiones folclóricas como única forma de afirmación. (2010: 233)

Así, "el folclor ha venido a ser una de las formas de lucha por la nacionalidad. Una bandera formidable que no puede ser arrebatada por el enemigo." (2010: 236).

Es claro que para Manuel Zapata Olivella "El folclor es la huella viva de la historia en el alma de los pueblos. Por eso, al hablar del folclor hispanoamericano en cualquiera de sus modalidades o regiones, surge el mestizaje como aporte de las razas que se fundieron en el gran escenario de América.” (2010:121). En este contexto, Manuel Zapata Olivella decidió reivindicar el mestizaje, pero aquel que surgió del "pueblo vivo, acechante, ansioso de presencia y afirmación” (2010:199); pueblo diverso y heterogéneo en el que el loriqueño encontró las "Razones del mestizaje folclórico colombiano" (1960). Entonces, a diferencia de la mirada que tenían el expresidente Laureano Gómez y los intelectuales y políticos Luis López de Mesa y de Miguel Jiménez López sobre el mestizaje como degenerativo de la raza colombiana (Pisano, 2010; y Wade, 1993), Manuel Zapata

${ }^{4}$ Por otro lado, aun cuando no profundiza en ello, el comentario "no existiera el mismo desapego por el estudio de muchas de las comunidades indígenas de nuestro país [...]", sugiere un cuestionamiento a los estudios indigenistas. Habrá que seguir indagando al respecto en otro momento. 
Carlos Alberto Valderrama Renteria

Olivella defendió, y, de hecho, encumbró como punto de partida de su proyecto racial y nacionalista, el folclore de los sectores populares: "La lucha mundial de los pueblos oprimidos que reclaman sus nacionalismos nos sorprende cuando tomamos conciencia de nuestro mestizaje racial y cultural" (2010: 166). El mestizaje de los pueblos oprimidos como proyecto racial se levantó contra la imposición cultural de unas élites colombianas y latinoamericanas aferradas a los valores y principios occidentales del desarrollo nacional: "Esta élite criolla no tenía ningún interés en reivindicar el folclor nacional de sus propios pueblos. Por el contrario, asumía la misma actitud del colonizador, interesada en borrar todas aquellas prácticas que, a su juicio, constituían muestras de barbarie" (2010: 234). Occidentalismo periférico que buscó la eliminación y el silenciamiento de la presencia de la gente negra e indígena. Por lo anterior, me quedan pocas dudas de que el sentido asignado a la idea de mestizaje en el pensamiento de Manuel Zapata Olivella fue reivindicar y reposicionar un proyecto racial y cultural que observó en el pueblo vivo que estudio por muchos años. Y aunque "El folclor [mestizo] como afirmación de la nacionalidad" (1967) fue su proyecto intelectual, su mirada del mismo no fue ingenua ni romántica. Él entendió que

aun en ese mismo pueblo hay que hacer claridades, porque las discriminaciones impuestas por el conquistador por muchos siglos, dejan todavía sec[u]elas de discrepancias raciales entre los mestizos del pueblo. [Surge] la vieja lucha entre el indio y el hispano, entre esclavos y esclavistas, entre negros e indios, que se manifiesta en el rechazo a los aportes de una u otra cultura, sin comprender el nuevo fenómeno de la nacionalidad que los aglutina y enfrenta unidos a las nuevas formas de colonización imperialista. (2010: 237)

La mirada del mestizaje en Manuel Zapata tampoco es descontextualizada. Observó que el mestizaje asumió matices y características regionales, como bien lo han señalado Viveros (2013) y Zapata-Cortés (2010). Aunque de manera ambigua y contradictoria, Manuel Zapata entendió el mestizaje como un resultado de las relaciones de poder raciales en Colombia y en Latinoamérica. Primero en la colonia y la esclavitud: "El menosprecio que asumió el conquistador hacia la cultura de los pueblos oprimidos, unas veces destruyendo las tradiciones y otras despreciándolas, mantuvo al folclor en una condición de paria, de elemento prohibido." (2010: 233. Cursivas añadidas). Y luego, en la constitución de las repúblicas latinoamericanas: "En la propia alma del criollo prosiguió la auto-discriminación de las expresiones nativas" (2010: 233. Cursivas añadidas). En este contexto de opresión colonial y postcolonial, las comunidades negras desarrollarán una

doble actitud: por un lado, voluntariamente asimila, roba, se nutre de la cultura ambiental. En Colombia la del hispano, la del indio y la que ya se integraba entre estos dos. Por otra parte, sufre la imposición del amo, quien lo obliga a tomar la suya o la que ya ha impuesto al mestizo. En estas circunstancias, exteriormente, la elección es imposible, debe someterse al yugo. (2010: 225)

\section{$[\ldots]$}


Así surgió el mestizaje triétnico que hemos visto en las formas materiales de la aculturación folclórica y en la cultura general. (2010: 227)

A pesar de estos procesos de imposición cultural, Manuel Zapata asumió el proyecto anti-racista de generar "conciencia del mestizaje, tomando de su folclor, de su cultura, de su significado popular" (2010: 237) los elementos que constituyen y defienden la nación colombiana de los neo-imperialismos. Fue, entonces, el "hermoso crisol de sentimientos que constituye el alma del pueblo colombiano [...] el emblema representativo [...] de la hispanoamericanidad, [...] [y] de la actitud comprensiva de pueblos unidos por una humanidad fraterna" (2010:124) lo que Manuel Zapata Olivella propuso defender en su pensamiento crítico y en sus acciones políticas.

Si consideramos lo desarrollado en el presente escrito, además de los posteriores trabajos en los que Manuel Zapata Olivella trabajó sobre el mestizaje, tenemos que reconocer que su trayectoria evidencia una agenda intelectual y política de carácter antirracista. Agenda que presenta varios énfasis en la idea de mestizaje. Lo presentado aquí da cuenta de cómo el autor usó el folclore de los grupos negros, indígenas y blancos-mestizos para hablar de un mestizaje cultural, denunciar el racismo y re-posicionar las culturas subalternas. En otros trabajos, Manuel Zapata describió el mestizaje como forma de explotación y opresión (2010: 297). En su trabajo "Identidad del negro en América Latina" sostuvo que,

El problema, sin embargo, no es de simple pigmentación. Desde muy temprano, el negro en la América Latina tuvo conciencia de su etnia, y actuó [...]. Pero conciencia del color no es sinónimo de plena identidad étnica y cultural. La piel ha sido el instrumento socorrido por el colonialista europeo para imponer su supremacía, lo que ha generado una corriente alienadora que obligaba y obliga a que negros, indios, mulatos y zambos traten de blanquear su piel para parecerse al amo. En esta forma, la identidad recorre ocultos caminos de negación étnica. El interés consciente no es el de ser, sino el de estar ubicado en una mejor posición de acuerdo con las reglas del blanco. Ese complejo se revela consecuentemente en el mestizo, sea cual fuese el cruce de sangre o el grado de fusión. Pero, paradójicamente, en el proceso de autoblanqueo, para mejor acomodarse a la mirada y complacencia del amo, el negro puro no se mira a sí mismo como tal. Se olvida de su color y de su origen africano y, contrariando toda evidencia, se proclama blanco. (Zapata Olivella, 2010:341-2. Cursivas añadidas)

En otros trabajos cuestiona categorías pensadas exclusivamente para cuerpos negros como en "Negritud, Indianidad y Mestizaje" (2010: 23) o en "La negredumbre en García Márquez" (1998). Ambos con un énfasis cultural. En "Indianidad y africanidad en la génesis del hombre americano" (2010: 378), Manuel Zapata sitúa el mestizaje mucho más allá de lo negro, lo blanco y lo indígena para mostrarnos las diferentes razas y grupos sociales que históricamente han alimentado el mestizaje en América Latina. Ya en su trabajo "Afroamérica, siglo XXI: tecnologías e identidad cultural" (2010: 39) remplaza su idea del "pueblo vivo" por "gigante afroamericano", nombre que reconoce las mezclas raciales en América Latina, pero cuya punta de lanza por la liberación son las comunidades descendientes de africanos y sus culturas. En este sentido, desde una perspectiva 
Carlos Alberto Valderrama Renteria

afrodiaspórica, hay un posicionamiento epistémico y protagonismo político por la liberación de América en su idea del gigante afroamericano que lo ha encontrado en la idea abstracta del Tercer Mundo.

Finalmente, en sus trabajos Las claves mágicas de América Latina (1998) y La rebelión de los genes (1997), Manuel Zapata Olivella sitúa la discusión del mestizaje no solo en la cultura, la historia, la política y la explotación del pueblo vivo, sino también en el ADN: mestizajes con énfasis en asuntos biológicos y consanguíneos. Entonces, el mestizaje fue una agenda antirracista que hizo parte de la trayectoria intelectual y política de Manuel Zapata Olivella. Agenda que busco siempre la desestructuración de los fundamentos y principios epistemológicos del racismo occidental: binarismos que niegan la influencia mutua entre dos cuerpos racializados y esencialismos culturales, raciales y biológicos que se contienen en sí mismos. En la agenda de Manuel Zapata Olivella se rompe con ellos, tal y como los estudios postcoloniales y culturales lo vienen planteando recientemente (ver, por ejemplo, Curiel, 2007; Hall, 1993; y Gilroy, 1993).

\section{Comentarios Finales}

El presente escrito exploró sentidos alternativos sobre mestizaje. Se entendió como un campo de confrontación política e ideológica entre regímenes de conocimiento y poder que se disputan su hegemonía y el control discursivo sobre su significado. Aquí, se hizo énfasis sobre los sentidos que Manuel Zapata Olivella le otorgó a la idea de mestizaje en contraposición a lo hecho por la elite colombiana. Una posible conclusión sería que el mestizaje fue una apuesta anti-racista consistente en denunciar el racismo y, por otro lado, revalorar y reafirmar la cultura popular del pueblo vivo; pueblo cuya base cultural fueron las transculturaciones africanas.

La reivindicación del "pueblo vivo" partió de su propia conciencia: una triple conciencia racial de su ser. A diferencia del intelectual afroamericano W.E.B. Dubois (1989), que reconoce el conflicto racial entre el mundo blanco y el negro, entre la herencias del mundo europeo y las herencias del mundo africano, Manuel Zapata Olivella reconoce que el pueblo vivo y su propio ser son el resultado de la siempre compleja y tensa relación de tres mundos: el africano, el europeo y el indígena; triple conciencia racial que se aproxima mucho a lo señalado por Stuart Hall (1993) sobre las presencias identitarias que contiene la experiencia afrodiaspórica: la presencia africana, la americana y la europea. Por otro lado, al igual que W.E.B. Dubois, Manuel Zapata Olivella se rehusó a descartar alguna de sus influencias raciales y culturales. Como lo expresara W.E.B. Dubois acerca de los aportes que el mundo americano blanco y el africano tienen para el mundo, lo analizado aquí demuestra que Manuel Zapata Olivella valoró lo que las herencias europeas blanco-criollas-mestizas, indígenas y africanas tienen para ofrecer al mundo: un mestizaje racial y cultural que rompe con los binarismos absolutistas que emergieron con la modernidad occidental (ver, por ejemplo, Gilroy, 1993).

Los escritos y artículos de Manuel Zapata Olivella analizados aquí muestran una fuerte influencia de los estudios afroamericanistas de mitad de siglo XX, y predominantes en Brasil, México y Cuba. 
Como observamos, Manuel Zapata vio la necesidad de crear un Centro de Estudios Afrocolombianos para estudiar las herencias (sobrevivencias) de las culturas africanas en Colombia y América Latina ${ }^{5}$. A pesar de esta evidente influencia, considero que la manera en que Manuel Zapata Olivella entendió el mestizaje como el resultado de circunstancias históricas, geográficas y raciales que prohijaron síntesis unitarias de las culturas (Zapata Olivella, 2010:121), no solo se distanció de la mirada culturalista de las mezclas raciales y culturales per se (dado su desconocimiento de las relaciones de poder racial), sino que también reveló las condiciones sociales (racismo), culturales (desprecio por las culturas indígenas y negras), económicas (esclavitud) y políticas (resistencias culturales) en las que el mestizaje tuvo lugar. Así, mestizaje en Manuel Zapata Olivella se refiere a procesos y condiciones y no a una cuestión mecánica con un resultado pre-determinado como se puede deducir en los textos de Fernando Ortiz "Las fases de la integración racial en Cuba" (1993:141) y "El proceso de la transculturación en Cuba" (1993:144), o de la raza cósmica de José Vasconcelos ([1948] 2003).

En este recorrido, he podido registrar la manera como Manuel Zapata Olivella describió las profundas implicaciones epistémicas, culturales y sociales del racismo en las nacientes ciencias sociales, las relaciones sociales y culturales de afrocolombianos, indígenas y blancos-mestizos del país. Lo anterior demuestra que previo a trabajos como Chango, el gran putas, La rebelión de los genes, Las claves mágicas de América Latina, los Congresos de la Cultura Negra de las Américas, entre otros, Manuel Zapata Olivella ya venía, desde un registro cultural, develando el racismo a la colombiana a través de su idea de mestizaje. Podemos decir que su sentido del término fue alternativo a los discursos hegemónicos del mestizaje, ya que su propuesta tuvo un carácter inclusivista de las diferencias raciales y culturales. Sin embargo, no fue una alternativa al mestizaje. Manuel Zapata Olivella no pudo desligarse del término para proponer un término nuevo, similar a lo que la feminista Lélia González propuso, tiempos después, contra la idea de lo latino. Según Ochy Curiel, Gonzáles denunció el eurocentrismo instalado en la idea de latino, dado que "subestima o descarta las dimensiones indígenas y negras en la construcción de las Américas” (Curiel, 2007: 98). Así, amefricanidad buscó reconocer el "proceso histórico de resistencia, de reinterpretación, de creación de nuevas formas culturales, que tiene referencias en modelos africanos pero que rescata otras experiencias históricas y culturales" (Curiel, 2007: 99). Por otro lado, y siguiendo los cuestionamientos hechos por Ochy Curiel a las teorías postcolonial y decolonial, la idea de mestizaje de Manuel Zapata Olivella desconoció las experiencias de las mujeres.

Por último, veo mucho de lo que Paul Gilroy (1993) señaló como la política de la realización (politics of fulfilment) en el pensamiento crítico y las acciones políticas de Manuel Zapata Olivella. Para Gilroy, la política de la realización se refiere a la noción que cultivaron algunos intelectuales

\footnotetext{
${ }^{5}$ Particularmente, fueron evidentes las influencias del mexicano José Vasconcelos y del cubano Fernando Ortiz. Del primero, fue importante su idea de raza cósmica. En los trabajos de revisados de Manuel Zapata, aparece la idea de cósmico en tres diferentes maneras. El "espíritu cósmico" (Zapata Olivella, 2010:59), el "contexto cósmico" (Zapata Olivella, 2010:365) y el "hombre cósmico de José Vasconcelos" (Zapata Olivella, 2010:393), haciendo alusión a las mezclas raciales y culturales de los grupos negros, indígenas y blancos. La influencia de Fernando Ortiz se expresó mejor en la idea de transculturación cultural. Manuel Zapata escribió sobre la transculturación africana (ver arriba).
} 
Carlos Alberto Valderrama Renteria

negros de una sociedad futura que fuera capaz de llevar a cabo las promesas sociales y políticas que la sociedad presente dejó incompletas (Gilroy, 1993: 37). Por ejemplo, la eliminación del racismo, la discriminación racial y el trato igualitario. En este sentido, la idea de mestizaje de Manuel Zapata Olivella refleja una realidad social informada y alimentada por sus acciones políticas desde su postura y defensa de la cultura del Caribe colombiano, la realización de la marcha del Día del Negro, la formación de organizaciones culturales y académicas como el Centro de Estudios Afrocolombianos, Letras Nacionales, la Fundación Colombiana de Investigaciones Folklóricas, entre otras, agrupaciones folclóricas y tertulias donde se discutió lo afrocolombiano. En este sentido, sus reflexiones, escritos, novelas, ensayos y activismo cultural reflejan su deseo de una política de la realización de lo que significaba el mestizaje en una sociedad como Colombia y la latinoamericana. Así, la política de la realización del mestizaje de Manuel Zapata puede ser vista como llena de contradicciones y ambigüedades (ver, por ejemplo, Viveros, 2013; y Zapata-Cortés, 2010), dado su deseo de una sociedad que cumpla con las promesas democráticas del liberalismo moderno. Libre de racismo. No olvidemos que, aunque radical y crítico, Manuel Zapata Olivella fue un pensador de corte liberal.

\section{BIBLIOGRAFÍA}

Appelbaum, N., Macpherson, A. y Rosemblatt, K. (2003). Introduction. En: Race and Nation in Modern Latin America (pp. 1-31). Chapel Hill and London: University of North Caroline Press, US.

Arboleda Quiñones, S., (2010). El mestizaje radical de Manuel Zapata Olivella: raza, etnia y ciudadanía. En: Rosero-Labbe, C., Lao-Montes, A. y Rodríguez, C. (Eds.) Debates sobre ciudadanía y políticas raciales en las Américas Negras (pp. 441-465). Bogotá: Universidad Nacional de Colombia.

Caicedo, J. (2013). A mano alzada... memoria escrita de la diáspora intelectual afrocolombiana. Popayán: Sentipensar.

Curiel, O. (2007). Crítica poscolonial desde las prácticas políticas del feminismo antirracista. Nómadas, (26), 92-101.

De la Cadena, M. (2000). Indigenous Mestizos: The politics of Race and Culture in Cuzco, Peru, 1919-1991. Durham, NY: Duke University Press, US.

De la Cadena, M. (2006). ¿Son los mestizos híbridos? las políticas conceptuales de las identidades andina. Universitas Humanística, (61), 51-84.

Dubois, W. E. B. (1989). The Souls of Black Folk. New York: Fawcett Publications 
Friedemann, N. S. de (1984). Estudios de negros en la antropología colombiana: presencia e invisibilidad. En Friedemann, N. y Arocha, J. (Eds.), Un siglo de investigación social (pp. 507-572). Bogotá: Etno.

Hall, S. (1993). Cultural identity and diaspora. En Williams y Chrisman (Eds). Colonial Discourse and Post-Colonial Theory (pp. 392-403). Londres: Harvester.

Gilroy, P. (1993). The Black Atlantic: Double Consciousness and Modernity. Cambridge: Harvard University Press.

Karabalí, M. (1947). Estudio del negro en Colombia. Cromos, (64), 9.

Mallon, F. (1996). Constructing mestizaje in Latin America: Authenticity, Marginality and Gender in the Claiming of Ethnic Identities. Journal of Latin American Anthropology, 2(1), 171-180.

Millán de Benavides, C.; Castro Gómez, S. y Hoyos V. G. (2013). Pensamiento colombiano del siglo XX, Tomo III. Bogotá: Pontificia Universidad Javeriana.

Múnera, A. (2010). Manuel Zapata y la nación inclusiva. En Por los senderos de sus ancestros (pp. 11-43). Bogotá: Colección de literatura afrocolombiana. Ministerio de Cultura.

Omi, M. and Winant, H. (1994). Racial Formation in the United States from the 1960s to the 1990s. New York: Routledge.

Ortiz, F. (1993). Etnia y sociedad. La Habana: Pensamiento Cubano.

Pisano, P. (2010). Liderazgo político negro en Colombia 1947-1964. Bogotá: Universidad Nacional de Colombia. Facultad de Ciencia Humanas. Departamento de Historia.

Valderrama, C. (2013). Folclore, raza y racismo en la política cultural e intelectual de Delia Zapata Olivella. El campo político-intelectual afrocolombiano. Revista CS, (12), 259296.

Valderrama, C. (2019). La diferancia cultural negra en Colombia. Contrapúblicos afrocolombianos. Revista CS, (29), 209-242. https://doi.org/10.18046/recs.i29.3631

Vasconcelos, J. ([1948] 2003). La raza cósmica. La misión de la raza Iberoamericana. Biblioteca Virtual Universal. Link: https://www.biblioteca.org.ar/libros/1289.pdf 
Carlos Alberto Valderrama Renteria

Viveros, M. (2013). Manuel Zapata Olivella 1920-2004. En Millán de Benevides, C.; Castro Gómez, S. y Hoyos V. G. (Eds.). Pensamiento Colombiano del siglo XX, Tomo III. Bogotá: Pontificia Universidad Javeriana.

Wade, P. (1993). Blackness and race Mixture. The dynamic of racial identity in Colombia. Baltimore: The Johns Hopkins University Press.

Wade, P. (2000). Music, Race and Nation: Música tropical in Colombia. Chicago: The University of Chicago Press.

Wade, P. (2005). Rethinking Mestizaje: Ideology and Lived Experience. Journal of Latin American Studies, 37(2), 239-257.

Zapata-Cortes, C. (2010). Mestizaje nacional: una historia "negra" por contar. Memoria y Sociedad, 14(29), 91-105.

Zapata Olivella, M. (13 de agosto de 1956). ¿Qué sabemos de los negros en Colombia? Cromos, pp. 32-34.

Zapata Olivella, M. (1961). Caña de millo, variedad y ejecución. Revista Colombiana de folclore. II(6), 155-159.

Zapata Olivella, M. (1963). Tres fuentes de la artesanía colombiana. Revista Colombiana de folclore. $\operatorname{III}(8), 147-150$.

Zapata Olivella, M. (1985). Presentación. En Zapata Olivella, D. y Massa Zapata, E. Manual de Danzas de la Costa Pacífica de Colombia. Bogotá: Colegio Máximo de las Academias Colombianas. Patronato Colombiano de Artes y Ciencias. Fundación Joaquín Piñeros Corpas. Junta Nacional de Folclor.

Zapata Olivella, M. (1990). Levántate Mulato: Por mi raza hablará el espíritu. Bogotá: Rei Andes.

Zapata Olivella, M. (1997). La rebelión de los genes. El mestizaje americano en la sociedad futura. Bogotá: Ediciones Altamira.

Zapata Olivella, M. (1998a). La negredumbre en García Márquez. En Memorias del XX Congreso Nacional de Literatura, Lingüística y Semiótica: Cien años de soledad, Treinta Años Después (pp. 107-112). Bogotá: Caro y Cuervo, Universidad Nacional de Colombia.

Zapata Olivella, M (1998b). Las claves mágicas de América Latina. Bogotá: Plaza \& Janés. 
Zapata Olivella, M. (2010). Manuel Zapata Olivella. Por los senderos de sus ancestros. Textos escogidos. Bogotá: Colección de literatura afrocolombiana. Ministerio de Cultura. 